\title{
External Branch of the Superior Laryngeal Nerve: Anatomy and Operating Hurts
}

\author{
Abdoulaye Kanté1,2*, Babou Ba², Youssouf Sidibée , Drissa Ouattara1, Bréhima Bengaly¹, \\ Bréhima Coulibaly¹, Drissa Traoré1, Mariam Daou ${ }^{4}$, Tata Touré2, Siaka Diallo', \\ Amady Diakalia Coulibaly5, Mamadou Alymami Keita6, Souleymane Sanogo6, Djibril Traoré1, \\ Moustapha Issa Magané ${ }^{7}$, Ousmane Ibrahim Touré1, Idrissa Tounkara ${ }^{4}$, Abdoulaye Diarra ${ }^{4}$, \\ Bakary Keita7 , Timbely Guidérè6, Birama Togola1', Nouhoum Ongoïba ${ }^{1,2}$
}

${ }^{1}$ Service of Surgery, CHU, Bamako, Mali

${ }^{2}$ Laboratory of Anatomy of the Faculty of Medicine and Odontostomatology, Bamako, Mali

${ }^{3}$ ENT and Head and Neck Surgery Department, CHU Mother-Child "Luxembourg", Bamako, Mali

${ }^{4}$ Service of Neurology, CHU Gabriel Touré, Bamako, Mali

${ }^{5}$ Department of Stomatology and Maxillofacial Surgery, CHU-CNOS, Bamako, Mali

${ }^{6}$ Service of General Surgery, CHU Gabriel Touré, Bamako, Mali

${ }^{7}$ Service of Anesthesia and Resuscitation, CHU Gabriel Touré, Bamako, Mali

Email: *kanteim@yahoo.fr

How to cite this paper: Kanté, A., Ba, B., Sidibé, Y., Ouattara, D., Bengaly, B., Coulibaly, B., Traoré, D., Daou, M., Touré, T., Diallo, S., Coulibaly, A.D., Keita, M.A., Sanogo, S., Traoré, D., Magané, M.I., Touré, O.I., Tounkara, I., Diarra, A., Keita, B., Guidérè, T., Togola, B. and Ongoïba, N. (2018) External Branch of the Superior Laryngeal Nerve: Anatomy and Operating Hurts. International Journal of Otolaryngology and Head \& Neck Surgery, 7, 388395.

https://doi.org/10.4236/ijohns.2018.76039

Received: October 1, 2018

Accepted: October 31, 2018

Published: November 30, 2018

Copyright (c) 2018 by authors and Scientific Research Publishing Inc. This work is licensed under the Creative Commons Attribution International License (CC BY 4.0).

http://creativecommons.org/licenses/by/4.0/ CC) (i) Open Access

\begin{abstract}
Purpose: Our purpose was to describe the anatomy of the external branch of the upper laryngeal nerve and to estimate the frequency of nerves at risk during the total thyroidectomies sub. Methodology: We realized in the $\mathrm{CHU}$ Point $\mathrm{G}$ in Bamako a forward-looking study over a period going from September 1st, 2016 till December 31st, 2017. All the patients operated by thyroidectomies subtotals for mild goiters were included to whom a systematic location of the external branch of the superior laryngeal nerve in the space avascular of Reeve was realized. Cancers and other thyroid pathologies were not included. Results: We counted and operated 120 cases of mild goiters. The external branch of the superior laryngeal nerve was seen and dissected in $80.8 \%$; it was not seen in $19.2 \%$. According to the classification of Cernea: the type 2 was found in $80.8 \%$ of the cases with him under typical $2 \mathrm{~b}$ in $47.5 \%$ and under type 2a in 40 (33.3\%). The global frequency of lesion of the external branch of the upper laryngeal nerve was $10.8 \%$ at 9 patients among whom 6 who presented a BENLS of Type Ni. Conclusion: The external branch of the upper laryngeal nerve of type 2 presents a risk of wound because the surgeon treats the upper pedicle at the level of the critical centimeter place over the upper pole of the thyroid. The identification of the nerve during the thyroid surgery is the solution of choice.
\end{abstract}




\section{Keywords}

External Branch of the Laryngeal Superior Nerve, Anatomy, Thyroid Surgery

\section{Introduction}

The subjective disorders of the voice are frequent after thyroid surgery without lesion of the recurring nerve [1] [2]. We incriminate the external branch of the upper laryngeal nerve (BENLS) or the external laryngeal nerve. The external laryngeal nerve innervates the crico-thyroid muscle which is a muscle tensor of vocal cords.

Consequently, the lesion of this nerve is responsible for a fatigability of the voice, for a modification of its tone which becomes graver as well as of disorders of the gulp.

He has an intimate and variable route with the upper thyroid pedicle what explains its vulnerability during the thyroid surgery [3]. It is necessary to know well the anatomical variations of its route to allow a careful dissection, so avoiding hurting it. Most of the surgeons prefer to avoid it rather than looking for it. But the latter run the inevitable risk of hurting nerves with low route which grind the upper thyroid pedicle.

\section{Materials and Methods}

\subsection{Patients}

We realized a forward-looking study from September 1st, 2016 till December 31st, 2017 in the service of surgery B of the university hospital G-spot of Bamako.

All the patients operated in the service for mild goiters were retained. Cancers and other thyroid pathologies were not included.

The diagnosis of mild goiter was paused by the histological examination realized on all the operating rooms.

\subsection{Method}

The group of hyperthyroid patients was handled medically with antithyroid ones of synthesis to have an eutthyroïdie before being scheduled for the surgical operation.

A complete clinical examination, an ultrasound, a dosage of free T3, T4, ultrasensitive TSH, preoperative biological balance sheet and cervical ultrasound were made at all the patients. The patients all had a consultation systematic ORL meadow and operating comment to study the mobility of vocal cords. For the operation, the sick person is installed in dorsal decubitus. The head is put in hyper extension by means of a block placed under the shoulders. The latter are lowered at the most to release well the neck. The way at first was a transverse cervicotomie type Kocher. 
After section of the platysma muscle of the neck, the previous jugular veins are ligatured and split. An unsticking is made between the venous plan ventrally, the sterno-cleido-mastoid muscles dorsally and laterally, and the sterno-thyroid muscles dorsally and medially. The unsticking achieves crânialement the lower edge of the thyroid cartilage and caudally the upper edge of the manubrium sternal. A median vertical section is then realized up to the thyroid capsule. No muscle is cut in this way at first. The thyroid capsule is opened. Sterno-thyroid muscle were reclined to allow a better exhibition on the junction develop the muscle of lower constrictor, of crico-thyroid muscle. The lower laryngeal nerve was identified and dissected since the region rétrosternale until its penetration in the larynx to allow a better mobilization of the lower pole of the thyroid. Then we proceeded to a dissection of the face medial of the upper pole of the thyroid gland. Then we retracted laterally and caudally the thyroid gland to expose the crico-thyroid muscle. The nerve was identified in the space. The terminal segment of the BENLS is contained in the region of the triangle bounded crânialement sterno-thyro-laryngeal and ventrally by the sterno thyroid, caudally muscle by the upper pole of the thyroid gland and medially by the thyroid and cricoid cartilages .Il give nervous twigs for the thyroid gland and for the muscle lower constrictor of the pharynx, to end in the crico-thyroid muscle.

The BENLS crosses behind the upper thyroid pediclecranio-caudally and latero-medially. This level of crossing is for the origin of the classification of Cernea according to which we grouped the various found anatomical variants. Indeed Cernea and al [4] described a simple classification with aim to predict the hurts of the external laryngeal nerve during the ligature of the upper thyroid pedicle (Figure 1).

The nerve which crosses the superior thyroid pedicle over $1 \mathrm{~cm}$ of the upper edge of the thyroid is classified typify 1 . That passing below is classified type 2 . Under type $2 \mathrm{a}$ corresponds to a crossing in the centimeter over the upper pole of the thyroid.

The subtype $2 \mathrm{~b}$ takes place below the upper pole of the thyroid. And the latter represents a nerve to high risk of wound during the ligature of the pedicle. As for the type $\mathrm{Ni}$, he corresponds to a nerve which was not identified in the triangle sterno-thyro-laryngeal. And it is generally a nerve branches of which distal penetrate into the muscle lower constrictor and walks below him.

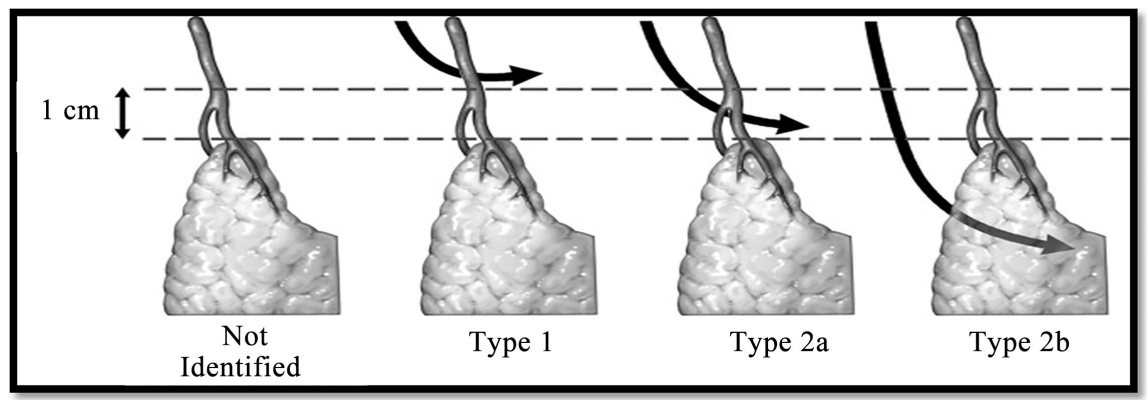

Figure 1. Cernea BENLS's classification with regard to the upper thyroid pedicle. 
We defined by lesion of the BENLS any fatigability of the voice or the modification of its tone or disorders of the gulp appeared in operating comment, which persists one month, and which is not secondary in a lower laryngeal lesion of the nerve.

The data were seized and analyzed on the software Ear information (version 6). The test of $\mathrm{X}^{2}$ and Student were used to compare our results with those of the literature. The threshold of meaning was fixed to 0.05 .

\section{Results}

We dissected 120 nerves during thyroidectomies subtotals. Photo 1 shows a type $2 \mathrm{~b}$ of the external branch of the superior laryngeal nerve.

\subsection{Sociodemographic Data}

The average age of the patients was of 37 years with extremes of 22 years and 69 years, slice from 22 years to 40 years represented $61.5 \%$. It was about 105 women and 15 men, 32 (26.7\%) lived in Bamako whereas 88 came from 11 regions of Mali and $86(71.7 \%)$ had a low socioeconomic level.

\subsection{Anatomo-Pathological Data}

The histological examination was made at all the sick, we found a goiter colloid in $77 \%$. At 64 sick a micro-follicular goiter, 32 macrofollicular goiters and 24 microcomputing-macrofolliculaires. The goiter was hyperplasique hyperfunctional at 59 sick (49.2\%), hyperplasique hypofunctional at 61 sick (50.8\%).

The reserved etiologies was: multi-goiter-heterosexual-nodulaire toxin: 31 (25.8\%), sick person of Basedow: 17 (14.3\%), basedowifié goiter: 7 (5.8\%) and a hyperthyroid unique nodule: 4 (3.3\%), hypofunctional goiter: 61 (50.8\%).

\subsection{Rate of Identification of the External Laryngeal Nerve According to the Surgical Technique}

The BENLS was 120 times looked for; it was seen and dissected in 97 cases (80.8\%); it was not seen in 23 cases $(19.2 \%)$

So we classified nerves identified according to the classification of Cernea: we did not find a nerve of type 1 . On the other hand the type 2 was found in 97 cases with him under type $2 \mathrm{~b}$ in 57 cases (47.5\%) and typical money $2 \mathrm{a}$ in 40 cases (33.3\%) (Figure 2).

\subsection{Complications Operating and Typical Comment of the External laryngeal Nerve}

The global frequency of lesion of the BENLS according to our definition was 9 cases $(10.8 \%)$.

Consequently, the morbidity was $10.8 \%$ (9 cases): it was about subjective disorders of the voice to type of fatigability in $7.2 \%$ (6 cases) and of disorders of the gulp in $3.6 \%$ (53 cases). Among the sick having presented a complication operating comment 6 were classified type Nor. The mortality was nil (Figure 3). 


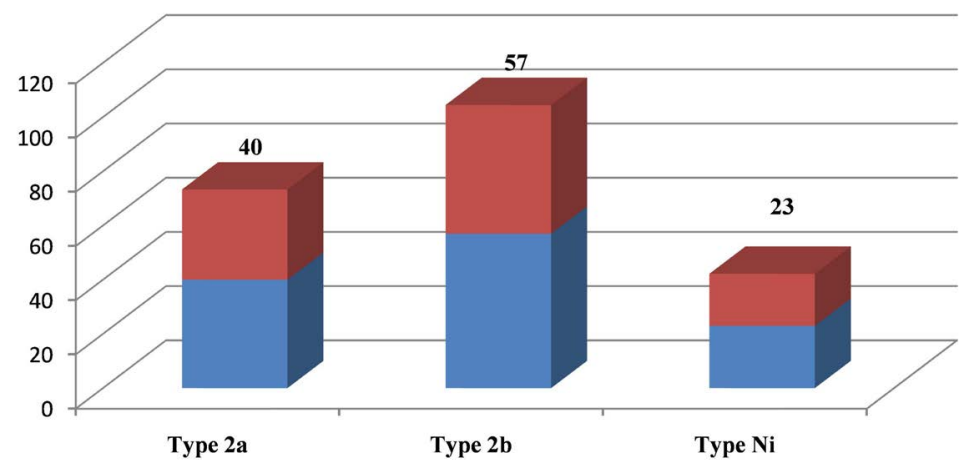

Figure 2. Distribution of the types of BENLS.

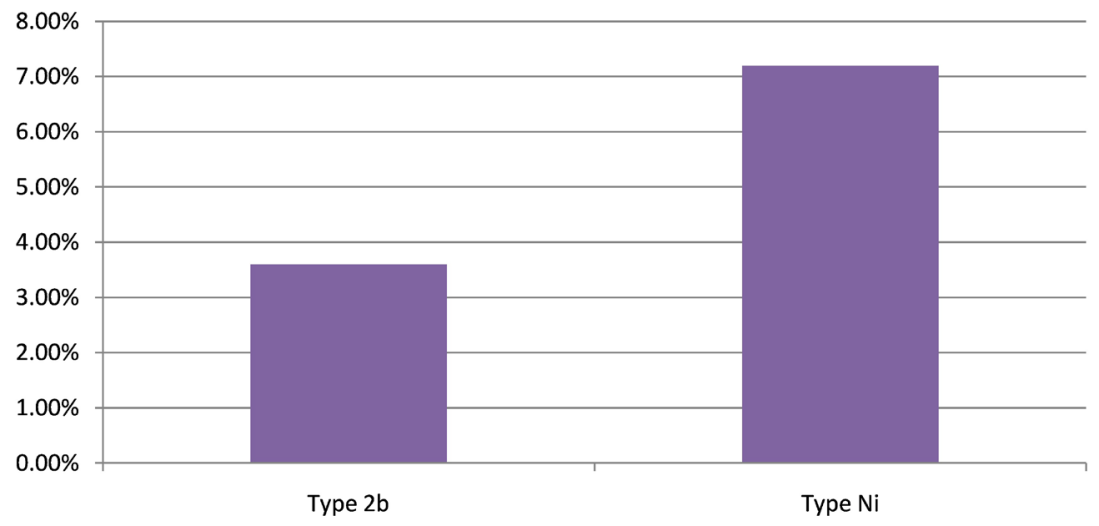

Figure 3. Distribution of nerves at the patients who presented complications post-operative.

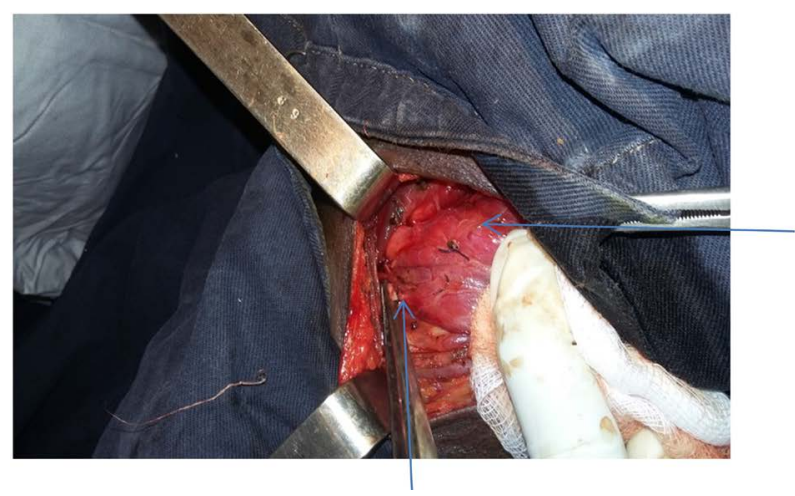

Thyroid gland reclined downward

Photo 1. BENLS typifies $2 \mathrm{~b}$.

\section{Discussion}

\subsection{Frequency}

The frequency of the hyperthyroid goiters in the indications of thyroidectomies is variously estimated by the authors. Our frequency was $49.2 \%$, this high frequency is brought reported by several authors: Koumaré [5] 56.16\% for a size of $\mathrm{n}=816(\mathrm{p}=0.0001)$; Togo [6] 34.56\% $\mathrm{n}=102(\mathrm{p}=0.0005)$; Megherbi [7] 38.4\%. These rates are superior to those of Rio [8] which found $17 \% \mathrm{n}=672(\mathrm{p}=$ $0.0003)$. 


\subsection{Age and Sex}

The goiter is pathology of the young adult. The average age of our sick was of 37 years with extremes of 22 years and 69 years. This young age is brought reported by other African authors [5] [9] who found respectively $35 \pm 13.5$ years and 32 years.

According to several studies [5] [6] [7], the female genital organ is more represented in the thyroid pathologies. We counted 7 women for a man. This is in compliance with the data of the literature.

\subsection{Rate of Identification of the External Laryngeal Nerve According to the Surgical Technique}

The identification of the BENLS is made according to several techniques. In our series the rate of identification of the external laryngeal nerve was $(80.8 \%)$. This rate is comparable to that of the literature. [10] [11] [12] [17].

We used the same technique as Aina and Hisham [10] who dissected 202 nerves in the space avascular of Reeve. The latter used, besides, the nervous monitoring. Their rate of identification was $92.3 \% .16$ nerves were not identified among which 7 were already operated on the thyroid and 6 presented malignant thyroid pathology.

Bellantone [13] used the same technique as Moosman and Deweese [3] which described the triangle sterno-thyro-laryngé to look for 215 BENLS, the success rate was $88.4 \%$.

In the USA, Friedman [14] [15] Dissected 2357 nerves by the technique of identification distal at the level of the junction develop the muscle of lower constrictor and of crico-thyroid muscle and followed the nerve in a reactionary way. His Rate of success was $85.1 \%$ of the cases.

Fu-Jie in china [16] dissected 86 anatomical subjects by using as the lower horn of the thyroid cartilage spots and located the penetration of the BENLS in the crico-thyroid muscle has $1.5 \mathrm{~cm}$ medially of the horn inferior.

All these techniques were assisted by a nervous monitoring. Aina [10] showed that thanks to the monitoring the rate of detection of the nerves of type 1 passed from $14.8 \%$ to $30 \%$.

\subsection{Estimation of the Risk}

Cernea [4] estimated the risk of lesion of the BENLS at $0 \%$ if we proceeded to his identification, against $12 \%$ if the sick person is operated by a senior without trying to identify the BENLS and $28 \%$ if the sick person is operated by a resident. Janson [17] estimated the risk at $58 \%$ if we do not try to identify the BENLS before the ligature of the superior thyroid artery.

On 120 cases of thyroidectomiessubtotals, we found 9 hurts (10.8\%) at the sick presenting a nerve of type $2 \mathrm{~b}$ and Nor. This frequency is comparable to that brought reported by Benyounes [18] who found $10 \%(\mathrm{n}=10)$ of lesion at the sick with a type $2 b$. 


\section{Conclusion}

The BENLS of type 2 presents a risk of wound because the surgeon treats the upper pedicle at the level of the critical centimeter places over the pole cranial of the thyroid. That is why the systematic identification of the nerve during the thyroid surgery is the solution of choice; requiring knowledge of the anatomical variations of this nerve. And she is helped by the location of the space avascular.

\section{Conflicts of Interest}

We, authors of this article declare that there is no conflict of interests.

\section{References}

[1] Lombardi, C.P., Raffaelli, M., D’Alatri, L., et al. (2006) Voice and Swallowing Changes after Thyroidectomy in Patients without Inferior Laryngeal Nerve Injuries. Surgery, 140, 1026-1032. https://doi.org/10.1016/j.surg.2006.08.008

[2] Sinagra, D.L., Montesinos, M.R., Tacchiv, A., et al. (2004) Voice Changes after Thyroidectomy without Recurrent Laryngeal Nerve Injury. Journal of the American College of Surgeons, 199, 556-560. https://doi.org/10.1016/j.jamcollsurg.2004.06.020

[3] Moosman, D.A. and Deweese, S.M. (1968) The External Laryngeal Nerve as Related to Thyroidectomy. Surgery, Gynecology, and Obstetrics, 127, 1011-1016.

[4] Cernea, C.R., Ferraz, A.R., Nishio, S., et al. (1992) Surgical Anatomy of the External Branch of the Superior Laryngeal Nerve. Head \& Neck, 14, 380-383.

[5] Koumaré, A.K., et al. (2000) Mild Goitrein Surgery in Mali (about 815 Cases). e-Memory of the National Academy of Surgery, 1, 16.

[6] Togo, A., Kanté, L., Diakité, I., Traoré, A., Maiga, A., et al. (2010) Hyperthyroid Mild Goiters in General Surgery CHU Gabriel Touré Mali: Epidemiological and Diagnostic Aspects. Médecine d' Afrique Noire, 56, 61-64.

[7] Megherbi, M.T., Graber, A., Alib, L., et al. (1992) Complications and Aftereffects of the Mild Thyroid Surgery. Surgery Journal, 112, 41-46.

[8] Rios, A., Jose, M. and Maria, D. (2005) Results of Surgery for Toxic Multi-Nodular Goiter. Surgery Today, 35, 9001-9006.

[9] Agoda, K., Adjenou, K., Amana, B., et al. (2008) Ultrasound Aspects of the Anomalies of the Thyroid Gland about 134 Cases. Méd. Afr. Black, 55, 573-578.

[10] Aina, N., Hisham, N. and Minusa, L. (2001) Laryngeal Nerve in Thyroid Surgery. Recognition and Surgical Implications. Surgery Journal, 71, 212-214.

[11] Pagedar, N.A. (2009) External Branch of the Superior Laryngeal Nerve. Operative Techniques in Otolaryngology, 20, 251-259.

[12] Nitin, A., Pagedar, S., Jeremy, L., et al. (2009) Identification of the External Branch of the Superior Laryngeal Nerve during Thyroidectomy. Archives of Otolaryngology-Head \& Neck Surgery, 135, 360-362. https://doi.org/10.1001/archoto.2009.9

[13] Bellantone, et al. (2001) Is the Identification of the External Branch of the Superior Laryngeal Nerve Mandatory in Thyroid Operation? Results of a Prospective Randomized Study. Surgery, 130, 1055-1059. https://doi.org/10.1067/msy.2001.118375

[14] Friedman, M., Meghan, N. and Ibrahim, H. (2009) Superior Laryngeal Nerve Identification and Preservation in Thyroidectomy. Operative Techniques in Otolaryngology, 20, 2. https://doi.org/10.1016/j.otot.2009.02.010 
[15] Friedman, M., Losalvio, P., Ibrahim, H., et al. (2002) Superior Laryngeal Nerve Identification and Preservation in Thyroidectomy. Archives of Otolaryngology-Head \& Neck Surgery, 128, 296-303. https://doi.org/10.1001/archotol.128.3.296

[16] Fu, J. (2010) Surgical Anatomy of the External Branch of the Superior Laryngeal Nerve in Chinese Adults and Its Clinical Applications. Head and Neck.

[17] Janson, S., Tisell, L., Hagne, I., et al. (1988) Partial SLN Lesions before and after Thyroid Surgery. World Journal of Surgery, 12, 522-527.

[18] Benyounes, N., Yassine, Y., Khalifa, Z., Lachkham, A., Kheireddine, N., Touati, S., et al. (2010) Anatomy of the External Laryngeal Nerve and Its Surgical Applications. Tunisian Journal of Otorhino Laryngology, 25, 36-41. 